\title{
Base definicional e ficha terminológica: etapas semiautomatizadas que auxiliam na elaboração de definições terminológicas
}

DOI: http://dx.doi.org/10.21165/el.v49i2.2572

\author{
Mirella Balestero' \\ Clotilde Murakawa ${ }^{2}$
}

\section{Resumo}

Com o advento da Informática, as pesquisas em Terminologia passaram a ser otimizadas, tornando mais rápida a obtenção dos resultados, das análises e dos produtos terminológicos. Por meio de tarefas semiautomatizadas, a execução de um trabalho terminológico pode auxiliar atividades que vão desde a elaboração do corpus até a elaboração de definições terminológicas, podendo gerar um glossário. Por conta disso, o objetivo, neste trabalho, é apresentar as etapas de elaboração da ficha terminológica e do incremento da base definicional, que são responsáveis, respectivamente, pelo registro das informações referentes a determinado termo e pelo registro de excertos definitórios cujos traços semânticos apresentam a descrição do conceito. As atividades foram sistematizadas no e-Termos e auxiliaram a elaboração das definições terminológicas dos termos da Revisão de Textos.

Palavras-chave: etapas semiautomatizadas; ferramentas computacionais; definições terminológicas; e-Termos.

1 Universidade Estadual Paulista "Júlio de Mesquita Filho" (UNESP), Araraquara, São Paulo, Brasil; msbalestero@gmail.com; https://orcid.org/0000-0001-9297-7238

2 Universidade Estadual Paulista "Júlio de Mesquita Filho" (UNESP), Araraquara, São Paulo, Brasil; jtm.jau@uol.com.br; https://orcid.org/0000-0002-3815-3534 


\title{
Definitional basis and terminology sheet: semi-automated steps that assist in the terminological definitions elaboration
}

\begin{abstract}
In advent of computer science, Terminology researches has been optimized, making the use of terminographic results, analysis and products faster. Through semi-automated tasks, the execution of a terminological work can assist activities ranging from the corpus to the terminological definitions elaboration, and may generate a glossary. In this paper, the objective is to present the stages of preparation of the terminology sheet and the incremental definitional basis, which are responsible, respectively, for registration of information relating to a particular term and definitive excerpts whose semantic features present the description of the concept. The activities were systematized in the e-Terms and assisted in terminological definitions elaboration of Proofreading terms.
\end{abstract}

Keywords: semi-automated steps; computational tools; terminological definitions; e-Terms.

\section{Introdução}

As primeiras contribuições da Informática nos estudos terminológicos datam de 1960, tornando mais rápida a sistematização dos domínios de especialidades e a elaboração de produtos terminológicos, como glossários, banco de dados, corpus etc. Nessa época, Wüster (1998) já admitia o caráter multidisciplinar da Terminologia, considerando a Informática uma das ciências que engloba a pesquisa terminológica e/ou terminográfica e reconhecendo a sua importância.

No Brasil, o interesse dos terminólogos pela Informática é bastante recente, aproximadamente 30 anos, cujos pioneiros foram os pesquisadores do Termisul ${ }^{3}$ (Projeto Terminológico Cone Sul), que surgiu em 1991 sob a liderança de Maria da Graça Krieger, do Instituto de Letras da Universidade Federal do Rio Grande do Sul. A partir daí, as ferramentas semiautomatizadas - como concordanciadores, analisadores de corpora, extrator e compilador de corpus, extrator de unidades lexicais, conversores automáticos -, passaram a ser utilizadas nas pesquisas linguísticas, sobretudo em Terminologia.

Em meados da década de 1980, começou-se a empregar o termo Terminótica, que representa a parceria entre Terminologia e Informática e constitui um marco para os estudos terminológicos, haja vista que as ferramentas computacionais auxiliam na

3 Para mais detalhes, acesse o site http://www.ufrgs.br/termisul/index.php. Acesso em: 07 ago. 2019. 
criação de "um conjunto de procedimentos automatizados ou semiautomatizados que deem suporte às tarefas do trabalho terminológico" (ALMEIDA; OLIVEIRA; ALUÍSIO, 2006). O uso deste termo foi intensificado a partir das reflexões de Almeida em 2010.

Contudo, é válido destacar que essas ferramentas são consideradas semiautomatizadas porque o computador não é capaz de executar, sozinho, uma análise qualitativa dos dados, por exemplo. Esta última depende tão somente do ser humano, que é, neste caso, o terminólogo.

Com base nisso, apresentamos o tema deste trabalho, um recorte das tarefas que foram executadas na dissertação da autora (BALESTERO, 2019). Trata-se de duas etapas semiautomatizadas que podem auxiliar a elaboração de definições terminológicas, a saber: a elaboração da ficha terminológica e o incremento da base definicional. Para desenvolver a pesquisa, tomamos como domínio de especialidade a Revisão de Textos.

Ademais, utilizamos o e-Termos, ambiente colaborativo gratuito que reúne todas as atividades terminológicas em apenas uma ferramenta. Mais à frente, faremos uma exposição do ambiente e das suas funcionalidades, bem como das etapas relevantes aqui.

\section{E-Termos}

Apesar de contarmos com uma grande variedade de ferramentas computacionais que auxiliam os trabalhos em Terminologia, a grande maioria não foi criada com o intuito de aprimorar os estudos terminológicos. Isso não significa, necessariamente, um problema, já que contamos, hoje, com programas muito bem elaborados e que auxiliam a elaboração de um corpus, geram listas de frequências, listas de concordanciadores, entre outros. No entanto, ainda faltava desenvolver um programa que englobasse todas as ferramentas em um só software.

A partir dessa necessidade, foi implementado, em 2009, o ambiente colaborativo e-Termos, por Leandro Henrique Mendonça de Oliveira. Acrônimo de Termos Eletrônicos, o e-Termos (figura 1) constitui-se como "um ambiente computacional que reúne um conjunto de ferramentas linguísticas e colaborativas interligadas a uma estrutura modular dedicada às tarefas e pesquisas terminológicas" (OLIVEIRA, 2009, p. 8) e segue os princípios terminológicos de base descritiva (CABRÉ, 1999). 
Figura 1. Tela inicial do e-Termos

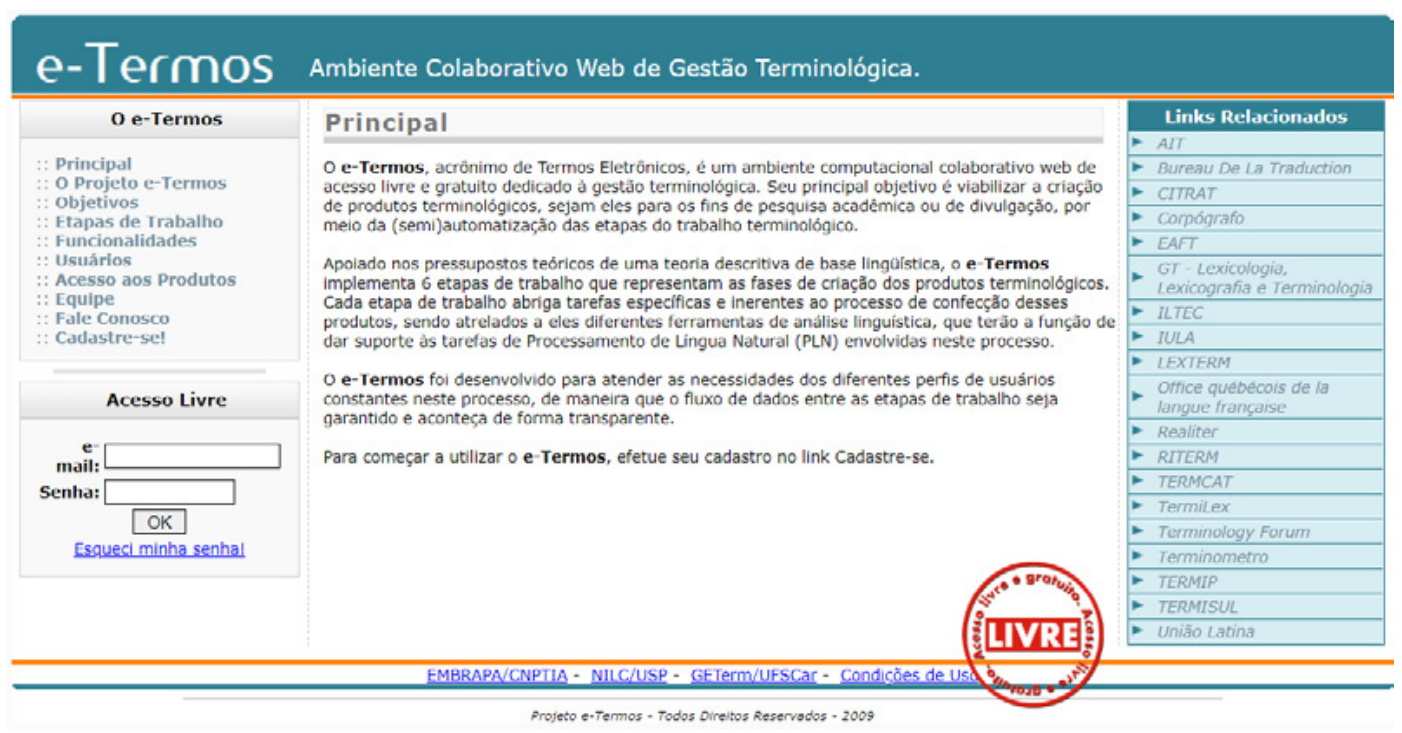

Fonte: e-Termos

Adotamos o e-Termos para desenvolver a pesquisa de mestrado devido às especificidades da ferramenta apontadas por Almeida, Oliveira e Aluísio (2006, p. 44), a saber:

1. a possibilidade de análise qualitativa do corpus; 2. a categorização e visualização dos termos em uma ontologia; 3 . a criação customizada das fichas terminológicas; 4. o gerenciamento da base definicional; 5. a redação assistida da definição terminológica; e 7 . a edição de verbetes a partir dos campos previamente selecionados nas fichas terminológicas.

Neste ambiente, há seis etapas terminológicas, explicitadas no quadro a seguir. 
Quadro 1. Etapas do e-Termos

\begin{tabular}{|c|c|c|c|}
\hline Etapa 1 & $\begin{array}{c}\text { Compilação automática } \\
\text { de corpus }\end{array}$ & $\begin{array}{c}\text { Responsável pela compilação automática do corpus } \\
\text { a partir do Portal de Corpus do Projeto PLN-Br. }\end{array}$ \\
\hline Etapa 2 & $\begin{array}{c}\text { Compilação e suporte } \\
\text { para análise de corpus }\end{array}$ & $\begin{array}{r}\text { Responsável pela compilação e análise quantitativa e } \\
\text { qualitativa dos corpora. }\end{array}$ \\
\hline Etapa 3 & $\begin{array}{c}\text { Extração automática de } \\
\text { candidatos a termos }\end{array}$ & $\begin{array}{c}\text { Responsável pela extração de candidatos a termos a } \\
\text { partir dos corpora de especialidade compilados. }\end{array}$ \\
\hline Etapa 4 & $\begin{array}{c}\text { Edição do mapa } \\
\text { conceitual }{ }^{4} \text { e }\end{array}$ & $\begin{array}{c}\text { Abriga as ferramentas de criação, edição e } \\
\text { visualização dos mapas conceituais, além dos } \\
\text { recursos computacionais para a inserção e a } \\
\text { avaliação dos termos pelos usuários especialistas. }\end{array}$ \\
\hline Etapa 6 & $\begin{array}{c}\text { Gerenciamento da base } \\
\text { de dados terminológicos }\end{array}$ & $\begin{array}{c}\text { Responsável pela criação e pelo preenchimento } \\
\text { da ficha terminológica e da elaboração da base } \\
\text { definicional. }\end{array}$ \\
\hline termos & $\begin{array}{c}\text { Responsável pela edição dos verbetes, pela difusão } \\
\text { e pelo intercâmbio dos produtos terminológicos } \\
\text { elaborados no ambiente. }\end{array}$ \\
\hline
\end{tabular}

Fonte: Balestero (2019), adaptado de Almeida e Oliveira (2013, p. 25-26)

Diferentemente de outros programas, o e-Termos é flexível (OLIVEIRA, 2009) e possibilita o uso das ferramentas independentemente, ou seja, é possível usar apenas uma etapa do e-Termos, dependendo do propósito do trabalho. Entretanto, para desenvolver este trabalho, foi necessário executar todas as tarefas devido à dificuldade de consolidação da Revisão de Textos, o que influencia a escassez de textos do domínio, a ausência de um corpus compilado até o momento da pesquisa, além da necessidade de definições terminológicas para minimizar a imprecisão dos termos.

Apresentamos, brevemente, a funcionalidade de cada etapa. Embora a primeira não esteja implementada, ela é importante para pesquisadores que queiram compilar o corpus de um domínio automaticamente, isto é, o e-Termos seleciona os textos da área por meio do Portal de Corpus. Uma alternativa para buscar as fontes é o emprego de palavras-chave nos navegadores da internet, bem como a seleção de textos acadêmicos, periódicos, revistas e sites relacionados ao domínio.

A etapa 2 é responsável pela compilação e análise do corpus. A partir dos textos selecionados pelo terminólogo, o e-Termos irá compilar o corpus e gerar, caso seja a

4 Neste trabalho, mapa conceitual, estrutura conceitual, árvore de domínio e ontologia são sinônimos. 
finalidade, listas de frequência, concordanciadores e quantidade de palavras do corpus ou de cada texto.

Na etapa 3, é possível extrair automaticamente os candidatos a termos de uma área de especialidade e, em seguida, editar as listas geradas para que sejam eliminadas aquelas unidades que não poderiam ser candidatos a termos.

Após a seleção dos candidatos a termos e da validação dessas listas por um especialista da área, categorizamos os termos em uma árvore de domínio, em outras palavras, elaboramos uma ontologia ${ }^{5}$. Com isso, determinamos, na etapa 4, as relações semânticas ${ }^{6}$ entre um termo e outro por meio de uma estrutura (que pode ser hierárquica ou não). Essa organização permite uma melhor visualização do domínio e de suas especificidades.

Já as tarefas que tomamos como objeto de análise neste trabalho estão implementadas na etapa 5. A elaboração da ficha terminológica é essencial para que as principais informações referentes a um termo sejam registradas. É a partir de um protocolo estabelecido entre terminólogo e especialista que conseguimos definir quais campos são relevantes para a área de especialidade e como esses campos serão preenchidos. Em síntese, foram propostos campos considerados essenciais na literatura, como entrada, classe morfológica, definição etc., além das informações referentes à data da elaboração da definição, contextos de uso, entre outras.

É nessa mesma etapa que a base definicional é incrementada. Isso significa que cada termo contém uma "bagagem", ou melhor, um conjunto de traços semânticos ${ }^{7}$ que o definem. Esses traços são percebidos nos contextos de uso ou contextos definitórios e auxiliam na etapa de elaboração da definição terminológica.

Por último, temos a etapa 6, responsável por editar e divulgar no ambiente os dados e produtos terminológicos.

\section{Base definicional e ficha terminológica}

Como mencionado anteriormente, precisamos entender o funcionamento das etapas anteriores à base definicional e à ficha terminológica para que essas atividades sejam

5 Ontologia e mapa conceitual são os termos usados pelo e-Termos.

6 São as relações que ocorrem entre dois ou mais termos, a saber: hiperonímia, hiponímia, cohiponímia, sinonímia, partitiva etc.

7 Trata-se das características de uma unidade léxica, ou seja, dos traços essenciais e recorrentes, imprescindíveis para sua identificação e definição. 
executadas de forma eficiente. Para isso, devemos nos atentar, principalmente, à etapa 4 , onde a estrutura conceitual é elaborada.

A estrutura conceitual se refere à elaboração de uma árvore de domínio por meio da organização dos termos a partir de suas relações semânticas. Assim, os termos são ligados por um nó, que representa um termo e nunca está sozinho, permanecendo sempre ligado a outro termo por meio de uma relação.

A seguir, a estrutura proposta para a Revisão de Textos:

Figura 2. Estrutura conceitual da Revisão de Textos

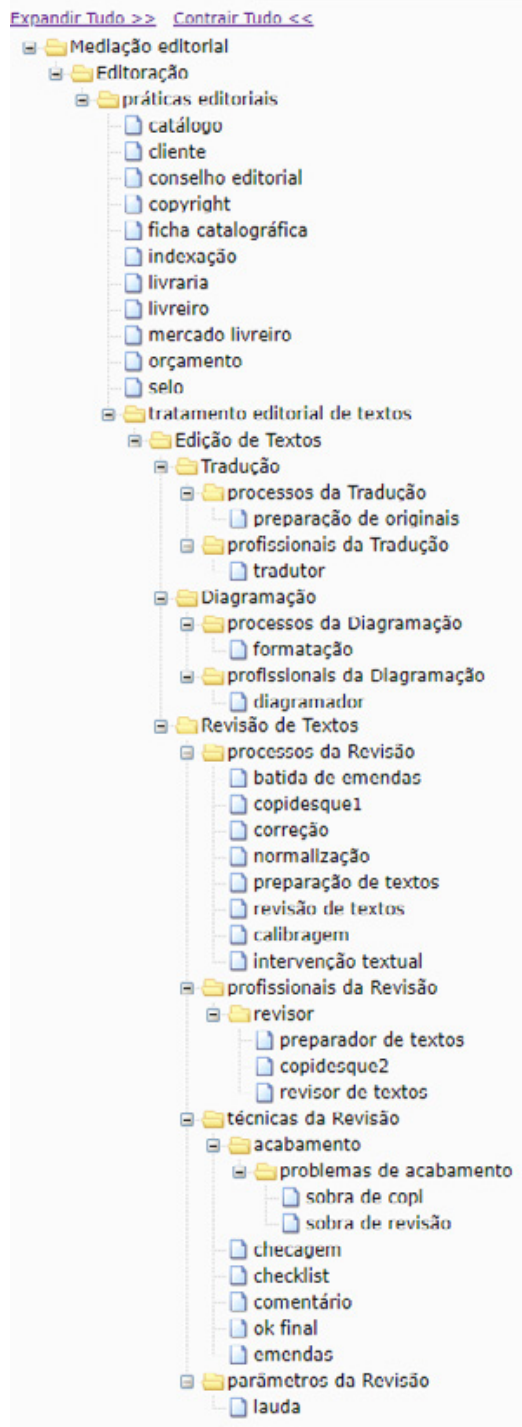

Fonte: e-Termos 
A ordem dos termos se justifica, em geral, por uma relação de hiperonímia, hiponímia ou co-hiponímia entre os termos, representando o funcionamento do campo. As pastas amarelas se referem aos elementos ordenadores, ou seja, termos que dispõem de alguma ordenação semântico-pragmática maior do que os outros, funcionando como um termo guarda-chuva. Já as "folhas" em azul constituem-se em campos menores semanticamente. Isto posto, percebemos que a estrutura conceitual é fundamental para executar as etapas seguintes, já que compreendemos, visualmente, as relações entre os termos.

Conforme exposto no quadro 1, a base definicional e a ficha terminológica contemplam a etapa 5 do e-Termos e dizem respeito ao registro dos contextos definitórios do termo e ao registro das informações referentes ao termo, respectivamente.

Nesse sentido, essas atividades, quando semiautomatizadas, otimizam o trabalho terminológico, haja vista que tornam mais rápida a busca pelos contextos definitórios, que podem ser extraídos pelo corpus ou por uma busca em outros ambientes, dentro e fora da Internet. No meio digital, podemos buscar excertos em dicionários eletrônicos, trabalhos publicados, sites, blogs, entre outros.

Não há fonte certa ou errada, tudo depende do propósito da pesquisa. Em outras palavras, alguns caminhos podem ser mais adequados, como foram as ferramentas de busca da internet para a Revisão de Textos. Estas se mostraram mais apropriadas para encontrar os textos da área, isso porque este domínio, ainda em consolidação, contém pesquisas muito recentes (duas últimas décadas) e a maioria delas estão on-line.

Em suma, a base definicional consiste em um repositório de informações sobre os termos e pode ser incrementada por diferentes suportes que sirvam como repertório para elaborar a definição. Incrementar a base definicional, portanto, significa selecionar um termo da estrutura conceitual e adicionar os excertos que contém alguma informação pertinente ao termo, buscando atribuir características a ele, ou seja, o que ele significa, sua função, onde circula etc.

Os traços semânticos variam de acordo com o que a unidade lexical representa no contexto de uso especializado, como o termo checagem, por exemplo, que pode se tratar de um processo a partir dos indícios do sufixo -agem. Para isso, buscamos excertos que tragam essas características inerentes ao termo, se realmente é um processo, de que forma ele ocorre, por que e onde.

Na figura 3, exibimos a base definicional do termo emendas preenchida. À esquerda, vemos os excertos e, à direita, a fonte deles: 
Figura 3. Base definicional do termo emendas

Termo: emendas

\begin{tabular}{|c|c|c|c|c|}
\hline Excerto & Fonte & Responsável & Data/Hora & Ação \\
\hline $\begin{array}{l}\text { essa é a etapa em que o diagramador recebe a prova revisada } \\
\text { pelo revisor de primeira prova para aplicar as correções, algo } \\
\text { mais conhecido como batida de emendas. A prova chega ao } \\
\text { diagramador com todas as indicações do revisor (correções e } \\
\text { sinais de revisão). O diagramador, logo, vai interpretar essas } \\
\text { indicações e corrigir os erros/fazer ajustes no arquivo digital } \\
\text { usando o software de diagramação. Ou seja, ele coloca a prova } \\
\text { impressa de um lado da mesa e aplica as correções no arquivo } \\
\text { digital, página a página. Depois disso, o arquivo digital (e } \\
\text { corrigido) é impresso novamente. /// o revisor de segunda } \\
\text { prova recebe a segunda prova impressa mais a primeira prova } \\
\text { impressa. Isso porque ele deverá fazer (antes de tudo) aquilo } \\
\text { que é conhecido como revisão espelhada (ou batida de } \\
\text { emendas): ele vai verificar se as correções da primeira prova } \\
\text { foram efetivamente aplicadas na segunda prova pelo } \\
\text { diagramador; se não foram aplicadas, o revisor de segunda } \\
\text { prova deve fazer isso agora. }\end{array}$ & https://revisao... & Julia Ferreira & $\begin{array}{c}\text { 2019-01- } \\
06 / 12: 30: 28\end{array}$ & $x \mathbb{1}$ \\
\hline $\begin{array}{l}\text { Emendas: As alterações de revisão que o revisor marca na } \\
\text { prova diagramada, as correções que devem ser feitas. // } \\
\text { Bater: Checar se as emendas foram corretamente passadas e, } \\
\text { logo, os erros corrigidos. // Prova suja: A prova diagramada } \\
\text { com as emendas do revisor para serem passadas pelo } \\
\text { diagramador para o PDF do livro. // Prova limpa: Quando o } \\
\text { diagramador já passou todas as emendas marcadas pelo } \\
\text { revisor na prova diagramada e esta já foi devidamente? } \\
\text { batida? (ou seja, alguém, possivelmente o editor, o assistente } \\
\text { editorial ou o próprio revisor, dependendo da forma de trabalho } \\
\text { da casa editorial, checou se todas e cada uma das emendas foi } \\
\text { corretamente passada para o PDF do livro). }\end{array}$ & https://oeulite... & Julia Ferreira & \begin{tabular}{|c|} 
2019-01- \\
$06 / 12: 34: 45$
\end{tabular} & $x \mathbb{1}$ \\
\hline $\begin{array}{l}\text { 1. verificar se todas as mudanças feitas pelo preparador } \\
\text { realmente foram passadas para a prova diagramada (bater } \\
\text { emenda, vide abaixo); /// Livro devolvido com a primeira } \\
\text { revisão, é hora de diagramar novamente com essas alterações. }\end{array}$ & & & & \\
\hline
\end{tabular}

Fonte: e-Termos

Importante destacar que, além dos excertos definitórios, há o nome do responsável pela tarefa com a data e o horário em que ela foi realizada, o que não impede que outras pessoas excluam excertos ou adicionem novos.

Recolhemos, no mínimo, quatro excertos definitórios para cada termo, haja vista que este número se mostrou suficiente, na maioria das vezes, para compreender o que o termo significa. Entretanto, quando possível, selecionamos mais textos, pois "quanto maior o número de excerto para cada termo, melhor, porque mais informações teremos sobre o termo a ser definido, o que ajuda a assegurar uma DT (definição terminológica) mais complexa" (BALESTERO; ALMEIDA; PIEROZZI JUNIOR, 2019, p. 13).

A partir dos excertos, foram detectados os traços semânticos dos termos, que contribuíram para a elaboração das definições terminológicas. No caso do termo emendas os traços são: etapa; alterações; alterações de revisão; prova; prova diagramada; correções; checar; checagem; verificar; mudanças. 
A ficha terminológica pode ser realizada concomitantemente ao incremento da base definicional. De acordo com Oliveira (2009, p. 80), a ficha funciona como um "registro completo e organizado de informações referentes a um dado termo, consistindo em um verdadeiro dossiê que contém todos os dados e elementos pertinentes ao objetivo da pesquisa". O protocolo da ficha contém os campos relevantes para determinado domínio e será exibido na figura 4.

Figura 4. Protocolo da ficha terminológica para o domínio da Revisão

\begin{tabular}{|c|c|c|c|c|}
\hline \multicolumn{5}{|c|}{ Nome do Protocolo: Fichas ReTex } \\
\hline \multirow{12}{*}{ Campos: } & Nome do Campo & Tlpo de Dado & Obrlgatórlo & Açăo \\
\hline & Termo & Texto & NÃO & $\times \geqslant$ \\
\hline & Morfologia & Morfologia & NÃO & $x=$ \\
\hline & Definicao & Definição & NÃO & $x=$ \\
\hline & Contexto & Texto & NÃO & $x=$ \\
\hline & Info_Encicl & Texto & NÃO & $x=$ \\
\hline & Sinonimos & Texto & NÃO & $x=$ \\
\hline & Daladacuiacau & Dald & NÃO & $x=$ \\
\hline & Datadarevis & Data & Nก̃o & $\times=$ \\
\hline & Terminologa & Texto & NÃO & $x=$ \\
\hline & Validadora & Texto & NÃO & $x=$ \\
\hline & Definicaoproposta & Texto & NÃO & $x=$ \\
\hline
\end{tabular}

Fonte: e-Termos

No caso da Revisão de Textos, os campos mais importantes para constar na ficha ${ }^{8}$ foram: termo, classe morfológica, definição, contexto, informação enciclopédica, sinônimos, data da criação da definição, data da criação da revisão, nome da terminóloga, validadora (especialista) e definição proposta (ou definição final).

Da mesma forma que é preciso clicar no termo para incrementar a sua base definicional, deve-se clicar no termo para preencher as fichas terminológicas. A título de exemplo, apresentamos a ficha terminológica do termo emendas preenchida.

8 Ao final da pesquisa, percebemos que alguns campos poderiam ser alterados e que novos campos poderiam aprimorar o diálogo entre terminólogo, especialista e orientador. Por isso, destacamos nas considerações finais da dissertação (BALESTERO, 2019) que o protocolo se mostrou suficiente para a pesquisa, muito embora poderia ser melhor adequado com alguns ajustes, como a inserção de um campo para cada informação da ficha, de forma que a especialista conseguisse dar sugestões em cada tempo, ficando, assim, uma espécie de informação comparativa (a da terminóloga e a sugerida pela especialista). 
Figura 5. Estrutura conceitual da Revisão de Textos em formato folder tree

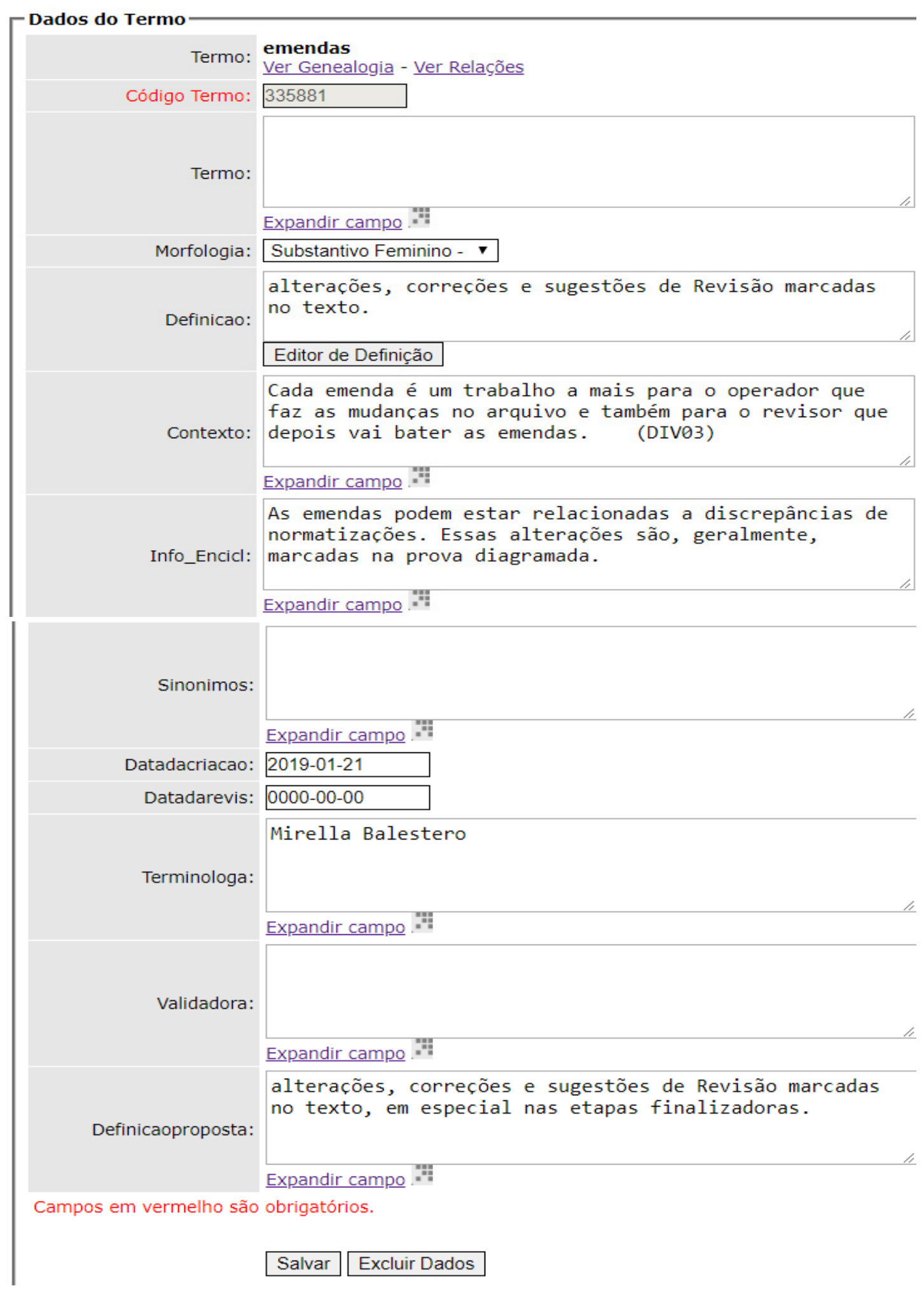

Fonte: e-Termos 
Nessa ficha, o código do termo foi gerado automaticamente pelo e-Termos. Além disso, há dois campos para colocar o termo, isso porque o ambiente já gera um campo para colocar a unidade lexical especializada, sem a necessidade de criar um para isso. Definição pode ser editado ao clicar em Editor de Definição. E o campo Sinônimos não foi preenchido porque o termo emendas não apresentou nenhum termo sinônimo. Por outro lado, emendas está relacionado com batida de emendas, que pode ser explicado em Informação enciclopédica.

As informações essenciais ao termo são registradas no campo Definição, enquanto as informações que não são fundamentais para a compreensão do significado do termo são colocadas na área Informações enciclopédicas.

Depois de pronta, as fichas terminológicas servem de base para que o terminólogo elabore as definições, e cabe a ele, junto ao especialista, decidir quais informações da ficha contemplarão o glossário.

Salientamos que tanto terminólogo quanto especialista de domínio como protagonistas ${ }^{9}$ do trabalho terminológico implicam discussões e dados positivos. Contudo, é pertinente pontuar que quando as atividades são executadas pelo terminólogo, as tarefas referentes às etapas 4 e 5 do e-Termos podem tornar-se mais claras no sentido de determinar 0 tipo de relação semântica entre os termos e elaborar as definições terminológicas. Isso porque o pesquisador conhece o percurso do trabalho e compreende as limitações e contribuições de cada uma das tarefas.

\section{Definição terminológica}

Definir um termo, assim como uma palavra ${ }^{10}$, é uma tarefa complexa, haja vista que se trata de uma unidade da língua, e quando falamos de língua devemos considerar a sua variabilidade e mudança. No sistema da língua, o léxico é a parte mais aberta e inconstante, pois é o reflexo de uma sociedade em um determinado período.

Assim sendo, a definição deve ser elaborada levando-se em consideração as questões sociais, culturais e pragmáticas de uma língua, considerando os sujeitos enunciadores e o contexto em questão (FINATTO, 2001). Em relação à definição terminológica, é preciso descrever os contextos especializados de uma área, buscando compreender e descrever o funcionamento do domínio. Embora alguns domínios sejam mais consolidados ou mais estáveis do que outros, a variação também é inerente ao léxico especializado.

9 Esta discussão foi feita por Balestero, Almeida e Pierozzi Junior (2019).

10 Entendemos por palavra, neste trabalho, a unidade lexical no contexto comum, usada no cotidiano. 
O conceito de definição varia de acordo com a perspectiva teórica e com o autor. Para Pavel e Nolet (2006, p. 23), a DT consiste em uma "fórmula lexicográfica que enuncia os traços semânticos distintivos de um conceito". Nesse sentido, Sager (1993) pontua que se trata de uma descrição linguística de um conceito baseada em uma lista de características.

Nessa mesma direção, Balestero (2019) retoma a ideia de Cabré (1993) em relação ao conceito da definição terminológica, que a considera uma expressão normalmente complexa equivalente semanticamente ao termo que define.

A elaboração do texto definitório pode seguir alguns modelos de definição ou algumas diretrizes ${ }^{11}$, mas não nos atentaremos em apresentá-los aqui. Além dos princípios teóricometodológicos que guiam a prática de definição, as atividades terminológicas elaboradas em ferramentas computacionais auxiliam a elaboração do texto definitório.

Desse modo, partir da leitura dos excertos definitórios da base definicional auxilia a elaboração das DTs, uma vez que as características do termo serão percebidas pela constante ocorrência de traços semânticos. E ainda, as informações relevantes para preencher a ficha terminológica auxiliam na organização desses traços, bem como na distinção entre quais características são essenciais e não essenciais para entender o significado do termo.

A título de exemplificação, apresentamos a seguir a definição do termo emendas:

(01) emendas (s.f.) alterações, correções e sugestões de Revisão marcadas no texto, em especial nas etapas finalizadoras.

Com esse exemplo, percebemos os traços semânticos (apresentados na seção anterior) observados nos contextos da base definicional, bem como a organização das informações em relação ao traço essencial e ao traço não essencial do termo. Deste modo, verificamos a eficiência de ambas as tarefas selecionadas como análise, a base definicional e a ficha terminológica, que se mostraram imprescindíveis para a elaboração da definição terminológica.

\section{Considerações finais}

Fazer um trabalho terminológico requer, entre outros aspectos, domínio da língua. Isso significa que, ao elaborar definições, por exemplo, o pesquisador pode e deve usufruir dos

11 A literatura da área é bastante rica nesse quesito. Vejam alguns nomes: Almeida, Souza e Pino (2007), Balestero, Almeida e Pierozzi Junior (2019), Domenéch (2014), Finatto (2001) e Termcat (2009). 
mecanismos linguísticos para refinar a redação da definição, adequando-a para o públicoalvo e para a sua finalidade. Outrossim, o conhecimento sobre a área de especialidade é fundamental, haja vista que os dados obtidos, neste caso a DT, devem ser claros e objetivos. Por essa razão, recomenda-se compreender o funcionamento do campo, o que implica reconhecer os processos e as práticas de revisão. Ademais, saber executar as tarefas terminológicas é importante na medida em que geram dados/resultados significativos.

Devido à complexidade de definir, esta tarefa torna-se mais eficiente quando da otimização das atividades por meio de ferramentas semiautomatizadas. Em vista disso, o e-Termos contribuiu para gerar informações pertinentes ao assunto, no sentido quantitativo, além de organizar os resultados e registrá-los em uma base definicional e em fichas terminológicas.

Tomadas como objeto de análise deste trabalho, as etapas de incremento da base definicional e de elaboração e preenchimento da ficha terminológica, mostram-se indispensáveis conhecimentos terminológicos e linguísticos para a elaboração das definições, pois representam, respectivamente, o registro dos contextos definitórios e o registro das principais informações sobreo termo. Além disso, quando semiautomatizadas, essas atividades tornam-se mais eficazes, como observado neste artigo.

Dessa forma, a parceria entre Terminologia e Informática é viável e, sobretudo, recomendada, já que toda tarefa semiautomatizada requer profissionais que analisem qualitativamente aquilo que o computador gera. Para finalizar, vale ressaltar que todas as atividades terminológicas, bem como as etapas do e-Termos, auxiliam a elaboração da definição.

\section{REFERÊNCIAS}

ALMEIDA, G. M. B. Fazer Terminologia é fazer Linguística. In: PERNA, C. L.; DELGADO, H. K.; FINATTO, M. J. (org.). Linguagens especializadas em Corpora: modos de dizer e interfaces de pesquisa. Porto Alegre: EDIPUCRS, 2010. p. 72-90.

ALMEIDA, G. M. B.; SOUZA, D. S. L. de; PINO, D. H. P. A definição nos dicionários especializados: proposta metodológica. RITerm - Debate terminológico, n. 3, p. 1-20, jan. 2007. Disponível em: https://seer.ufrgs.br/riterm/article/view/23812/13814. Acesso em: 02 ago. 2019.

ALMEIDA, G. M. B.; OLIVEIRA, L. H. M. de; ALUÍSIO, S. M. A Terminologia na era da Informática. Ciência e Cultura, Campinas, v. 58, n. 2, p. 42-45, 2006. Disponível em: https://bit.ly/300e8QH. Acesso em: 12 abr. 2019. 
BALESTERO, M. S. Definições terminológicas da Revisão de Textos: estudos iniciais para a elaboração de um glossário. 2019. Dissertação (Mestrado em Linguística e Língua Portuguesa) - Faculdade de Ciências e Letras, Universidade Estadual Paulista "Júlio de Mesquita Filho", Araraquara, 2019.

BALESTERO, M. S.; ALMEIDA, G. M. B; PIEROZZI JUNIOR, I. Quando o especialista de domínio e as novas tecnologias entram em cena: impactos na definição terminológica. Linguasagem, São Carlos: v. 30, n. 1, p. 1-27, 2019. Disponível em: https://bit.ly/2XdXFq4. Acesso em: 03 jun. 2019.

CABRÉ, M. T. La terminología: teoria, metodologia, aplicaciones. Barcelona: Editorial Antártida; Empúries, 1993.

CABRÉ, M. T. La terminología: representación y comunicación - elementos para una teoria de base comunicativa y outros artículos. Barcelona: Institut Universitari de Lingüistica Aplicada, 1999.

DOMÉNECH, E. V. Patrones de la definición terminológica en el ámbito de la cerámica. Una contribución a la automatización de las definiciones. Castelló de la Plana. 2014. Tese (Doutorado em Linguística) - Universitat Jaume I, Castelló de la Plana, 2014.

FINATTO, M. J. B. Definição terminológica: fundamentos teórico-metodológicos para sua descrição e explicação. 2001. Tese (Doutorado em Estudos da Linguagem) - Instituto de Letras, Universidade Federal do Rio Grande do Sul, Porto Alegre, 2001.

OLIVEIRA, L. H. M. de. e-Termos: um ambiente colaborativo web de gestão terminológica. 2009. Tese (Doutorado em Ciências da Computação e Matemática Computacional) - Instituto de Ciências Matemáticas e de Computação, Universidade de São Paulo, São Carlos, 2009. Disponível em: https://bit.ly/36G80Db. Acesso em: 07 ago. 2019.

PAVEL, S.; NOLET, D. Manual de Terminologia. Tradução Enilde Faulstich. [S.I.]: 2006.

SAGER, J. C. Curso práctico sobre el procesamiento de la terminología. Tradução Laura C. Moya. Madrid: Fundación Germán Sánchez Ruipérez/Pirámide, 1993.

TERMCAT, Centro de Terminologia. La definició terminològica. Vic: Eumo Editorial, 2009.

WÜSTER, E. Introducción a la teoría general de la terminología y a la lexicografía terminológica. Tradução Anne-Céceli Nokerman. Barcelona: Universitat Pompeu Fabra, 1998. 